\title{
НЕКОТОРЫЕ ВОПРОСЫ ПРАВОВОГО РЕГУЛИРОВАНИЯ МЕЖДУНАРОДНОГО НАУЧНО-ТЕХНИЧЕСКОГО СОТРУДНИЧЕСТВА В СФЕРЕ КОМПЛЕКСНОГО ИЗУЧЕНИЯ АРКТИКИ НА ПРИМЕРЕ СТРАН ЕВРОПЕЙСКОГО СОЮЗА"
}

\author{
(c) 2020 Ершова Ирина Владимировна \\ Высшая школа экономики, управления и права,
} доцент кафедры теории и истории государства и права, доцент, кандидат философских наук Северный (Арктический) федеральный университет имени М.В. Ломоносова, Россия, Архангельск E-mail: i.ershova@narfu.ru

\section{(c) 2020 Чертова Надежда Андреевна}

проректор по административной и правовой работе, профессор, доктор юридических наук, Высшая школа экономики, управления и права, заведующая кафедрой финансового права и правоведения, доктор юридических наук, профессор

Северный (Арктический) федеральный университет имени М. В.Ломоносова, Россия, Архангельск E-mail: chertova@narfu.ru

\section{(C) 2020 Богданова Елена Николаевна}

Гуманитарный институт, доцент кафедры экономики и менеджмента, доцент, кандидат экономических наук

Филиал Северного (Арктического) федерального университета имени М. В. Ломоносова в г. Северодвинске Архангельской области, Россия

E-mail: e.n.bogdanova@narfu.ru

\section{(c) 2020 Жура Светлана Егоровна}

Высшая школа экономики, управления и права,

доцент кафедры финансового права и правоведения, доцент, кандидат экономических наук Северный (Арктический) федеральный университет имени М. В.Ломоносова, Россия, Архангельск E-mail:s.zhura@narfu.ru

\section{(c) 2020 Савельев Иван Вячеславович}

Высшая школа экономики, управления и права, заведующий кафедрой международного права и сравнительного правоведения, кандидат исторических наук, доцент

Северный (Арктический) федеральный университет имени М. В.Ломоносова, Россия, Архангельск E-mail: i.savelev@narfu.ru

\section{(c) 2020 Тетерин Александр Викторович}

Высшая школа экономики, управления и права, доцент кафедры конституционного и муниципального права, кандидат юридических наук

Северный (Арктический) федеральный университет имени М. В.Ломоносова, Россия, Архангельск E-mail: a.teterin@narfu.ru

В настоящее время актуальным становится вопрос международного научно-технического сотрудничества в сфере комплексного изучения Арктики. Для согласования и гармонизации действий стран в аспекте выстраивания стратегии проведения научных исследований необходимо правовое регулирование данного процесса. В настоящей статье авторами рассматриваются некоторые нормативные положения стран ЕС по согласованию политики проведения научных исследований в Арктике.

Ключевые слова: правовое регулирование, международное научно-техническое сотрудничество, изучение Арктики

\footnotetext{
* исследование выполнено при финансовой поддержке РФФИ в рамках научного проекта № 18-29-15055 мк Разработка правовой модели международного научно-технического сотрудничества в сфере комплексного изучения Арктики
} 
Арктика является центром притяжения для проведения разнообразных исследований. Ученые многих стран фокусируют свое внимание на вопросах, связанных с экологией, биомониторингом, комплексной безопасностью, на что указывается в разработке стратегий освоения Арктики. Необходимость правового регулирования с целью гармонизации действий стран в контексте освоения Арктики очевидна, о чем свидетельствует большое количество опубликованных на сайте Европейского Союза документов. Для согласования своих стратегий по комплексному освоению Арктики государствам целесообразно объединить свои усилия в сфере научно- технического сотрудничества.

На сайте Европейского Союза (далее, ЕС) в разделе «Законодательство Европейского Союза» представлено более 9000 документов по тематике «Научно-техническое сотрудничество». Проанализировав представленную нормативную базу, можно выделить цель ЕС, приоритетные направления развития научно-технической сферы, преимущества и риски сотрудничества, выбор партнерской базы, арктический вектор исследований, совместные проекты со странами EC.

Одним из базовых актов является Договор о функционировании Европейского Союза. В ст.179 Раздела XIX «Научно-техническое развитие и космос» содержится нормативное закрепление целей ЕС в сфере научно-технической деятельности, среди которых перечисляются создание единого европейского пространства научных исследований с целью укрепления научных и технологических основ; создание благоприятных условий для развития конкурентоспособности, в частности, промышленной сферы; помощь в проведении научно-исследовательских мероприятий [3, ст.179].

Ст.180 закрепляет основные мероприятия, проводимые ЕС в научно-технической сфере, в числе которых отмечена реализация научноисследовательских, технологических и демонстрационных программ, содействие сотрудничеству с предприятиями, научно-исследовательскими центрами, университетами; поощрение сотрудничества с третьими странами и международными организациями по вопросам научных исследований, технологического развития и демонстрационных проектов, осуществляемых в ЕС; распространение и внедрение результатов научных исследований, технологического развития и демонстрационных проектов, осуществляемых в ЕС; помощь в подготовке и осуществлении мобильности исследователей в ЕС [3, ст.180].

Базовые правовые основы для регулирования исследовательской деятельности были заложены еще в договоре об учреждении Европейского Сообщества по атомной энергии (1957 г., является архивным, утратил юридическую силу). В гл.1 представлено правовое регулирование исследовательской деятельности. Важное нормативное положение содержится в ст.5 документа, где говорится о координирующей функции Комиссии и о недопустимости дублирующих друг друга научных исследованиях. Исследования должны проводится в тех сферах, которые недостаточно изучены [12, ст.5]. Ст.6 перечисляет меры поддержки научно-исследовательских инициатив посредством предоставления финансовой помощи в рамках научно-исследовательских контрактов; предоставление исходных материалов или специальных расщепляющих материалов для проведения исследований (бесплатно или за плату); предоставление установок, оборудования, экспертной помощи, предприятий (бесплатно либо за плату); использование софинансирования [12, ст.6]. Таким образом, акцентируется необходимость проведения новых, инновационных исследований. Идеи, заложенные в данном Договоре, прослеживаются в ряде иных актов Европейского Союза.

B «Докладе Комиссии Европейскому Парламенту, Совету и Палате Аудиторов по годовому отчету об управлении и исполнении бюджета ЕС за 2018 год» отмечается, что поддержка ЕС исследований и инноваций способствует сотрудничеству между исследовательскими группами в разных странах и обеспечивает междисциплинарный подход. Одна из основных задач указанных мероприятий заключается в появлении прорывных открытий в науке. Так, программа «Горизонт 2020» вносит вклад в достижение общей цели- повышение промышленного лидерства и конкурентоспособности Европы [11].

Интересным представляется Решение Европейского парламента и Совета «О подготовке и развитии статистики сообщества по науке и технике». Положения данного решения распространяются только на страны ЕС. В тексте подчеркивается необходимость создания базы статистических данных о научных исследованиях и разработках, технологических иннова- 
циях, науке и технике. Система статистической информации предназначена для регулирования научно-технической политики в Сообществе, оценки НИОКР и инновационного потенциала стран с целью управления структурными фондами. Разработанные статистические индикаторы способствуют обеспечению полной и достоверной информации о науке и технике, в том числе для измерения результатов научно-технической деятельности, распространения знаний и результатов инновационной деятельности. Эта информация необходима для оценки степени эффективности научно-технической политики в сфере экономики. Среди приоритетных направлений перечисляются инновации (технологические и нетехнологические); человеческие ресурсы (специалисты, задействованные в сфере науки и технологий); патенты (статистика по патентам, получаемая по данным национальных и европейских патентных ведомств); статистика высоких технологий (идентификация и классификация товаров и услуг, измерение экономических показателей и вклада в экономический рост) и иное [4].

Таким образом, на уровне принятых актов закрепляются приоритетные направления научно- технической политики и разработаны индикаторы статистических данных.

Для инвестирования в знания и инновации в целях повышения конкурентоспособности, роста и создания рабочих мест в Европейском Союзе на основании принятого Постановления Европейского парламента и Совета «О создании Европейского Института Инноваций и технологий» был основан Европейский институт инноваций и технологий, основной целью которого является содействие интеграции высшего образования, исследований и инноваций в странах ЕС. В документе отмечается необходимость поддержания высшего образования, как неотъемлемого компонента комплексной инновационной стратегии. Европейский институт инноваций и технологий содействует мобильности в рамках Европейского исследовательского пространства и пространства высшего образования, а также обеспечивает грантовую поддержку исследователей и студентов. На уровне нормативных актов подчеркивается важность триады, заложенной в основу Болонского процесса - единство образования, науки и инноваций. Европейский Институт Инноваций и технологий способствует созданию единого глобального европейского образовательного пространства [10].

Итак, в проанализированных документах указывается цель ЕС в сфере науки и инноваций - добиться глобального лидерства; определяются приоритетные направления, затрагивающие социально-экономическую сферу: сохранение здоровья населения, добыча и переработка сырья, устойчивые цепочки поставок от добычи ресурсов до потребителя, мобильность человеческих ресурсов.

Однако в достаточном количестве актов красной нитью прослеживается интерес ЕС к Арктике и арктическим исследованиям. ЕС разработал свое видение арктической политики.

Так, в рабочем документе о перечне мероприятий в рамках разработки арктической политики Европейского Союза, сопровождающем совместное Сообщение Европейскому парламенту и Совету «О разработке политики Европейского Союза в отношении Арктического региона: прогресс с 2008 года и последующие шаги» в п.1.3. «Исследования, мониторинг и оценка» вносится предложение о направлениях исследовательских программ: они должны учитывать состояние и изменения окружающей среды в Арктике, расширять возможности мониторинга и наблюдения и разрабатывать технологии, которые можно применить в арктических условиях. Указывается на междисциплинарный характер исследовательских проектов, в рамках которых объединяются естественные и экологические науки, в том числе затрагивающие здравоохранение и социально - экономическое направление государственной политики [8].

Тема Арктики, как правило, упоминается в документах в контексте экологической безопасности. В Сообщении Комиссии «Чистая планета для всех. Европейское стратегическое видение процветающей, современной, конкурентоспособной и экологичной экономики» выражается беспокойство со стороны ЕС о быстром таянии льдов в Арктике, что негативно сказывается на биоразнообразии в северном регионе и на средствах к существованию местного населения. В связи с вышеуказанными аспектами прогнозируются серьезные последствия для европейской экономики, инфраструктуры, производства продукции, общественного здоровья, биоразнообразия, а также политической стабильности [2]. Очевидно, что тематика экологической безопасности становится ключевой для проведения междисциплинарных исследований. Одним из 
направлений являются морские исследования.

В Сообщении Комиссии Европейскому парламенту, Совету, Европейскому экономическому и социальному комитету и Комитету регионов «О развитии международного аспекта комплексной морской политики Европейского Союза» подчеркивается роль науки и техники, как ключевых факторов для достижения устойчивого экономического роста в морской сфере. В Стратегии ЕС по морским исследованиям рекомендуется странам ЕС и партнерам из третьих стран расширить участие в крупномасштабных международных исследовательских программах, выходящих за рамки национальных глубоководных исследований. Это позволит выявлять общие интересы, преимущества и разработать коллективные меры реагирования на важные международные обязательства, наилучшим образом используя уже достигнутые результаты в текущих проектах с третьими странами, финансируемые в шестой и седьмой рамочных программ исследований [1].

Общие черты морской политики выявлены в ряде стран, которые обозначены в документе в качестве ключевых международных партнеров ЕС по данным исследованиям. К ним относятся Канада, Норвегия, Япония, США, Бразилия, Индия, Россия, Китай.

В рабочем сопроводительном документе к Совместному докладу Европейскому парламенту и Совету «О совершенствовании международного управления океаном - два года прогресса» приведен анализ сферы международного управления океаном. Подписание Соглашения о предотвращении нерегулируемого рыбного промысла в открытых водах центральной части Северного Ледовитого океана может заполнить пробел в системе управления океаном и законодательно защитит хрупкие арктические морские экосистемы. В соответствии с Соглашением планируется создание совместной программы научных исследований и мониторинга для изучения арктических морских экосистем. В п.14 настоящего документа говорится о масштабах международных океанологических исследований, инноваций и научном партнерстве. ОхватАтлантический океан от Арктики до Антарктиды. ЕС выделил более 60 млн. евро на 2018-2019 гг. для поддержки научного сотрудничества до 2020 г. Сотрудничество в области морских исследований и инноваций поспособствует решению проблем, связанных с Атлантическим океаном, включая наблюдение за океаном, продовольственную безопасность, полярные исследования и проблему изменения климата [9].

В п.8 Резолюции Европейского парламента «О Стратегии ЕС в Арктике» отмечается, что ЕС выступает за свободу исследований в Арктике и поддерживает междисциплинарный подход к исследованиям [6, п.8].

В документе закрепляются нормативные положения политики ЕС, направленной на укрепление высшего образования и научноисследовательских учреждений в регионе; подчеркивается важность поддержки сетевого сотрудничества между высшими учебными заведениями и предоставления возможностей финансирования исследований в целях обеспечения устойчивого экономического развития в регионах Арктики [6, п.46].

В Совместном Сообщении Европейскому парламенту и Совету представлена комплексная политика Европейского Союза в Арктике, разработанная в трех приоритетных областях: изменение климата и охрана окружающей среды в Арктике; устойчивое развитие Арктики; международное сотрудничество по вопросам Арктики.

В п.1.1. раздела «Политические меры» подчеркивается, что ЕС является крупным вкладчиком в арктические исследования. Как правило, финансирование арктических исследований проводится через программу «Горизонт 2020». Центральным элементом в области арктических исследований является программа EU - PolarNet, поддерживающая общеевропейский консорциум экспертов и инфраструктуры для полярных исследований с целью ассимилирования научного потенциала Европы в полярных регионах. Указанный проект предполагает работу с исследовательскими организациями из России и США. Инфраструктура и службы «Коперника» внесут вклад в исследовательскую деятельность в Арктике, включая мониторинг погоды, климатических изменений и толщины льда, а также совершенствование моделирования океана. Для ЕС важно обеспечить эффективное международное научное сотрудничество посредством поддержки транснационального доступа к исследовательской инфраструктуре для улучшения политических и экономических связей и поддержания хороших отношений с ключевыми странами региона [7].

В разделе «Устойчивое развитие Арктики» утверждается, что именно суровый климат Ар- 
ктики является идеальной инновационной площадкой для внедрения новых технологий и ноухау.

Согласно п.2.1. ЕС поддерживает развертывание инновационных технологий в Арктике. Программы Горизонт 2020, ESIF предусматривают финансирование научно-исследовательской и инновационной деятельности в европейской части Арктики. Отмечается, что связь между научными исследованиями, наукой и технологиями обеспечат устойчивое развитие стран ЕС.

В следующем разделе содержатся положения о международном сотрудничестве. ЕС заинтересован в том, чтобы Арктика оставалась зоной конструктивного диалога и международного сотрудничества. Наука рассматривается в качестве катализатора для совместного решения проблем, тем самым содействует мирному сотрудничеству. ЕС позиционирует себя в качестве мирового лидера в области науки, поэтому странам ЕС необходимо активно участие в крупномасштабном глобальном научном сотрудничестве. С учетом особой важности Арктического региона и происходящих в его рамках изменений, важным представляется сотрудничество ЕС в арктическими и неарктическими партнерами для определения общих позиций и решений по таким вопросам, как изменение климата, охрана окружающей среды и научные исследования. В качестве стратегических партнеров по арктическому региону ЕС выделяет государства, проявляющие интерес к Арктике. К ним относятся Индия, Китай, Республика Корея, Сингапур и Япония. Также арктическая политика остается важным элементом тесных отношений ЕС с Исландией и Норвегией [7].

Нормативные положения по научному сотрудничеству указывают на необходимость предоставления доступа к исследовательской инфраструктуре с целью улучшения политических и экономических связей и поддержания хороших отношений с ключевыми партнерами. EC развивает научное сотрудничество на международном уровне в рамках Трансатлантического океанического и Арктического исследовательского альянса. Более ста организаций, в т.ч. из Исландии, Норвегии, России сотрудничают в рамках Европейской сети морских наблюдений (EMODnet) с целью обеспечения доступа к peзультатам исследований [9].

В документах указывается на важность проведения исследований в области безопасности и обмена передовым опытом в этой сфере.

В Резолюции Европейского парламента «О комплексной политике Европейского Союза в Арктике» отмечаются три приоритетные сферы: изменение климата, устойчивое развитие и международное сотрудничество.

В п.48 Резолюции отмечается важность систематического и долгосрочного сбора данных, полученных в результате арктических исследовательских проектов. При этом выражается обеспокоенность по поводу того, что достижения отдельных проектов часто нивелируются при переходе от одного периода финансирования к другому. Таким образом возникает необходимость обеспечения преемственности при планировании арктических исследований на период после 2020 года [5, п.48].

Для обеспечения безопасного судоходства, экологического мониторинга и наблюдения за изменением климата в Арктике акцент смещается на развитие космических технологий и исследований космоса [5, п.49]. В целях содействия научным исследованиям и мониторингу климата, а также создания условий для развития, навигации и безопасности на море внесены предложения по укреплению телекоммуникационной инфраструктуры Арктики [5, п.57].

Итак, проанализировав нормативную базу ЕС, можно сделать следующие выводы.

В актах Европейского Союза по научно-техническому сотрудничеству закреплены основные положения, регулирующие данную сферу. Одним из базовых документов является Договор о функционировании Европейского Союза в части ст.ст.179-190, регулирующих научнотехническую деятельность. В последующих документах обозначена цель Европейского Союза достижение глобального лидерства в сфере науки и инноваций. Указанную цель можно достичь, реализуя триединство образования, науки и инноваций. В документах четко прописаны приоритетные сферы для проведения исследований, затрагивающих социально-экономическую сферу: здоровьесбережение, добыча и переработка сырьевых ресурсов, устойчивые цепочки поставок от добычи ресурсов до потребителя, мобильность человеческих ресурсов. Политика ЕС в сфере науки и инноваций направлена на укрепление научно-технической базы европейских предприятий для обеспечения их инновационности и конкурентоспособности на международном и региональном уровнях. 
На данный момент более 300 актов, представленных на сайте ЕС, содержат положения, затрагивающие вопросы Арктики. Европейский Союз последовательно разработал свое видение арктической политики, которая получила название «Стратегия ЕС в Арктике». В Стратегии указываются три приоритетные области: изменение климата и охрана окружающей среды в Арктике, устойчивое развитие Арктики, международное сотрудничество по вопросам Арктики. Исходя из обозначенных направлений определяются приоритеты в исследовательских программах: мониторинг состояния окружающей среды и изменение климата в Арктике, подчеркивается важность разработки технологий, которые можно применять в арктическом регионе. Красной нитью обозначена необходимость проведения междисциплинарных исследований.

С целью имплементации нормативных положений в сфере научно-технического сотрудничества, для ЕС важным аспектом является формирование партнерской базы. Согласно представленным актам, ключевым партнером по проведению морских и арктических исследований являются США. Стратегический интерес для стран ЕС представляют государства, заинтересованные в изучении Арктики (Индия, Китай, Республика Корея, Сингапур, Япония). Также EC разрабатывает «дорожные карты» международного сотрудничества в сфере науки и инноваций и выделяет ряд стран, объединенных в блок «Восточное партнерство». В «Восточное партнерство» входят Азербайджан, Армения, Беларусь, Грузия, Молдова и Украина. Приоритетными направлениями сотрудничества между ЕС и странами «Восточного партнерства» являются социальная сфера, демография, благосостояние, окружающая среда и климат, безопасная и читая энергетика. Однако возможность вовлечения стран «Восточного партнерства» в арктические исследования в документах не упоминается.

Отдельно рассматривается вопрос сотрудничества ЕС и России. Проанализировав действующие международные соглашения между Россией и странами ЕС, констатируем, что межстрановое сотрудничество охватывает приоритетные направления экономики, охраны окружающей среды, науку и образование. В рамках научного сотрудничества Россия рассматривается как перспективный партнер в контексте арктических исследований в части изучения изменения климата, авиации, энергетики, продовольствия, сельского хозяйства, биотехнологии, здравоохранения, исследования в области ИКТ, мобильности, нанотехнологий, исследовательской инфраструктуры, космических исследований.

Таким образом, ЕС предпринимает попытки создания единого, глобального научно-технического пространства, с особым акцентом на арктический вектор исследований, в рамках которого ключевым направлением выбрана сфера экологии (окружающая среда, изменение климата, морские исследования). При этом, формируя партнерскую базу, ЕС создает единое научно-исследовательское пространство, имеющие достаточно мощный научный потенциал, фундаментальные научные школы по определенным областям исследований. Интеграция межстрановых научных школ, ученых-исследователей осуществляется посредством их объединения в международные исследовательские группы в рамках программы «Горизонт 2020» и в следующей за ней программе «Горизонт-Европа» (рамочная программа исследований и инноваций на 2021-2027 гг.).

\section{Библиографический список}

1. Communication from the Commission to the European Parliament, the Council, the European Economic and Social Committee and the Committee of the Regions - Developing the international dimension of the Integrated Maritime Policy of the European Union /* COM/2009/0536 [Электронный ресурс] Режим доступа: https://eurlex.europa.eu/legal-content/EN/TXT/?uri=CELEX\%3A52009DC0536 (дата обращения: 20.07.2020 г.).

2. Communication from the Commission to the European Parliament, the Council, the European Economic and Social Committee and the Committee of the Regions and the European Investment Bank A Clean Planet for all A European strategic long-term vision for a prosperous, modern, competitive and climate neutral economy COM/2018/773 [Электронный ресурс] Режим доступа: https://eur-lex.europa.eu/legal-content/EN/ ALL/?uri=CELEX\%3A52018DC0773 (дата обращения: 20.07.2020 г.). 
3. Consolidated versions of the Treaty on European Union and the Treaty on the Functioning of the European Union - Consolidated version of the Treaty on the Functioning of the European Union - Protocols - Annexes Declarations annexed to the Final Act of the Intergovernmental Conference which adopted the Treaty of Lisbon, signed on 13 December 2007 - Tables of equivalences // Official Journal L C 326, 26.10.2012. - P. 0001-0390.

4. Decision No 1608/2003/EC of the European Parliament and of the Council of 22 July 2003 concerning the production and development of Community statistics on science and technology (Text with EEA relevance) // Official Journal L 230, 16.09.2003 - P. 0001-0003.

5. European Parliament resolution of 16 March 2017 on an integrated European Union policy for the Arctic (2016/2228(INI) (2018/C 263/19) // Official Journal of the European Union, 263/136, 25.7.2018. P. 136-147.

6. European Parliament resolution of 12 March 2014 on the EU strategy for the Arctic (2013/2595(RSP)) (2017/C 378/20) // Official Journal of the European Union C 378/174 9.11.2017, P. 174-181.

7. Joint communication to the European Parliament and the Council. An integrated European Union policy for the Arctic JOIN/2016/021 [Электронный ресурс] Режим доступа: https://eur-lex.europa.eu/legal-content/EN/ TXT/?uri=CELEX\%3A52016JC0021(дата обращения: 20.07.2020 г.).

8. Joint Communication to the European Parliament and the Council - Developing a European Union policy towards the Arctic region: progress since 2008 and next steps (JOIN (2012) 19 final of 26 June 2012). [Электронный ресурс] Режим доступа: https://eur-lex.europa.eu/legal-content/EN/LSU/?uri=CELEX:52012JC0019 (дата обращения: 20.07.2020 г.).

9. Joint Report to the European Parliament and the Council Improving International Ocean Governance - Two years of progress JOIN/2019/4 final [Электронный ресурс] Режим доступа: https://eur-lex.europa.eu/legal-content/ EN/TXT/?uri=JOIN:2019:4: FIN (дата обращения: 20.07.2020 г.).

10. Regulation (EC) No 294/2008 of the European Parliament and of the Council of 11 March 2008 establishing the European Institute of Innovation and Technology // Official Journal L 097, 9. 4.2008, p.1.

11. Report from the Commission to the European Parliament, the Council and the Court of Auditors. 2018 Annual Management and Performance Report for the EU Budget. 25.6.2019 [Электронный ресурс] Режим доступа: https://www.europarl.europa.eu/cmsdata/185182/COM_COM(2019)0299(ANN)_EN.pdf (дата обращения: 20.07.2020 г.).

12. Treaty establishing the European Atomic Energy Community (Euratom) [Электронный ресурс] Режим доступа: https://eur-lex.europa.eu/legal-content/EN/TXT/?uri=LEGISSUM: xy0024(дата обращения: 20.07.2020 г.). 